metabolic block is differential and variable'. Balsan et al. ${ }^{3}$ thought that the slightly greater requirement of patients with vitamin D-dependent rickets for $1 \alpha$-hydroxy $D_{3}$ compared with vitamin D-deficient patients threw some doubt on the site and type of the metabolic block in the former condition. They suggested that this might be due to factors related to the severity of 25 hydroxy $D_{3} 1$ - $\alpha$-hydroxylase deficiency.

In infants of similar age and size Balsan et al. ${ }^{4}$ reported a range of dosage requirements of cholecalciferol $\left(D_{3}\right)$ from 600 to $7660 \mu \mathrm{g}$ daily. Although most patients with vitamin D-dependent rickets who have been described so far have required large doses of cholecalciferol, Rosen and Finberg ${ }^{2}$ mentioned one child who was maintained on 1000 IU/24hours $(20 \mu \mathrm{g}) 25-\mathrm{OH} \mathrm{D}$. $_{\text {. }}$.

It might be expected that if the defect were less severe the presentation of affected patients would be later, and this is borne out to some extent in the reports. The majority of patients who have been reported were between 1 month and 2 years when they first came to medical attention and they have required up to $100000 \mathrm{IU}(2.5 \mathrm{mg}) \mathrm{D}_{3}$ daily. The patient of Rosen and Finberg, ${ }^{2}$ who required 3500 IU $(87.5 \mu \mathrm{g}) \mathrm{D}_{3}$ daily, did not present until he was aged $4 \frac{1}{2}$ years when his main symptom was clumsiness. An even older patient (14 years) in that series was investigated because he was the sibling of an affected infant. He was maintained on a relatively small dose of $5000 \mathrm{IU}(100 \mu \mathrm{g}) 25-\mathrm{OH} \mathrm{D} \mathrm{D}_{3}$ daily.

It would seem that our patient has relatively mild disease and therefore presented late. Nevertheless, in common with more severely affected individuals she requires the physiological dose of $1 \mu \mathrm{g} 1$ - $\alpha$-hydroxycholecalciferol daily.

\section{References \\ 1 Prader A, Illig R, Heierli E. Eine besondere Form der primären Vitamin D resistenten Rachitis mit Hypocal- cämie und autosomal dominantem Erbgang: die hereditare Pseudo-Mangelrachitis. Helv Paediatr Acta 1961; 16: 452-68. \\ 2 Rosen J F, Finberg L. Vitamin D-dependent rickets: action of parathyroid hormone and 25 hydroxychole- calciferol. Pediatr Res 1972; 6: 552-62. \\ 3 Balsan S, Garabedian M, Sorgniard R, Holick M F, De Luca H F. $1 \propto$ hydroxy vitamin D: a comparative study in children. In: Bickel H, Stern J, eds. Inborn errors of calcium and bone metabolism. Lancaster: MTP Press, 1976: 179-90. \\ 4 Balsan S, Garabedian M, Courtecuisse V, et al. Long- term therapy with $1 \propto$ hydroxyvitamin $D_{3}$ in children with 'pseudo-deficiency' rickets. Clin Endocrinol [Oxf] (Suppl) 1977; 7 : 225-30S.}

Correspondence to Dr Jennifer Cowen, Department of Child Health, Alder Hey Children's Hospital, Eaton Road, Liverpool L12 2AP.

\title{
Zinc-dependent chemotactic defect in an infant with acrodermatitis
}

\author{
L BUSINCO, A M MENGHI, P ROSSI, R D'AMELIO, AND E GALLI \\ First Department of Paediatrics and Second Department of Infectious Diseases, University of Rome
}

SUMMARY A 5-month-old infant developed acrodermatitis enteropathica when weaned from breast milk to cows' milk. Plasma zinc concentration was low. T- and B-lymphocyte functions were normal, but there was a severe defect of neutrophil chemotaxis. Oral treatment with zinc sulphate (40 mg daily) induced an immediate clinical improvement, with restoration of normal plasma zinc level and complete correction of neutrophil chemotaxis.

Acrodermatitis enteropathica (AE) is an autosomal recessive inherited disorder characterised by diarrhoea, failure to thrive, anorexia, a vesiculobullous eruption around the mouth, anus, hands, and feet, alopecia, photophobia, paronychia, and high susceptibility to Candida albicans and Pseudomonas aeruginosa infections. The disease can appear when the infant is weaned from breast milk to cows' milk. In the untreated child death results from overwhelming infections, superimposed on a chronic marasmic state. Until a few years ago treatment was empirical, and consisted of breast-milk feeds and the oral administration of halogen-substituted 8hydroxy-quinolines. ${ }^{1}$ In 1975 Moynahan $^{2}$ reported low levels of zinc in the plasma of AE patients and the successful treatment of the disorder with oral zinc salts, which brought about both an increase in the plasma zinc and clearance of symptoms. Eckhert et al. ${ }^{3}$ suggested that the disorder might be related to zinc metabolism, with low quantities of certain zinc-binding ligands of low molecular weight, which are essential for the absorption of the metal, and protect it from chelation by other dietary components. The immune system of affected children has shown various anomalies: delayed-hypersensitivity skin reactions negativity, lack of serum IgA and IgM and, more recently, neutrophil and monocyte chemotaxis defect. ${ }^{4-6}$

We report an infant with $\mathrm{AE}$ who also had a severe neutrophil chemotaxis defect in the presence of normal intrinsic motile capacity. A striking 
clinical improvement was observed after administration of zinc sulphate, $40 \mathrm{mg}$ a day orally. Complete recovery of directed cellular motility was also demonstrated.

\section{Materials and methods}

T- and B-lymphocytes were evaluated as reported previously. ${ }^{7}$ Leucocyte motile function was assessed by the agarose migration test of Nelson et al. ${ }^{8}$ with modifications. ${ }^{9}$ The migration index (MI) and the random migration index (RMI) were measured by the following formulae: $\mathrm{MI}=$ (number of chem cells-number of $R M$ cells) $\times$ (chem $D-$ RMD) $/ 100$

$\mathbf{R M I}=\mathbf{R M}$ cells $\times \mathbf{R M D} / 100$

In which, number of chem cells $=$ number of cells migrated towards the attractant stimulus

Number of RM cells = number of cells migrated towards the control well

Chem $\mathrm{D}=$ maximum distance of migration

$\mathrm{RMD}=$ random migration distance

Normal values: MI $522 \pm 222$, RMI $186 \pm 122$.

The bactericidal assay was assessed by the method of Quie using Staphylococcus aureus as a test strain; $;^{10}$ the results were expressed as the percentage of bacteria still viable after 120 minutes of incubation with neutrophils. Opsonisation, phagocytosis, and candidacidal activity were estimated by a micromethod previously described. ${ }^{11}$ Zinc was analysed by atomic absorption spectrometry. ${ }^{12}$

\section{Case report}

A 6-month-old white boy had been born at term, weighing $3100 \mathrm{~g}$. He had been exclusively breast fed for 3 months. Then, after starting cows' milk feeds, he gradually developed intractable diarrhoea, alopecia, and vesiculobullous lesions, and failed to thrive. He was admitted to two different hospitals with the diagnosis of epidermolysis bullosa. At 5 months, when he was admitted to this paediatric department, his weight was $4.5 \mathrm{~kg}$ (normal for an infant of 45 days), he was weak, apathetic, irritable, and anorectic. There were erythematous and vesiculobullous lesions on the face, trunk, and extremities, and in the perianal region. He lacked eyebrows and scalp hair. Oral candidiasis and severe paronychia of the fingers and toes were present. Routine laboratory examinations were all normal. Serum zinc level was $52 \mu \mathrm{g} / 100 \mathrm{ml}$ (normal 103 $\pm 9 \mu \mathrm{g} / 100 \mathrm{ml}$ for infants of this age).

\section{Immune system.}

Specific cellular immunity

The delayed skin test responses were as follows:
Candida ++ , SK-SD + , PPD - Lymphocyte mytogenic response to PHA was normal. Peripheral E-rosette-forming cells were $66 \%$ and $1247 / \mathrm{mm}^{3}$.

\section{Humoral immunity}

Serum immunoglobulin levels, IgG $560 \mathrm{mg} / 100 \mathrm{ml}$, IgA $30 \mathrm{mg} / 100 \mathrm{ml}$, and IgM $188 \mathrm{mg} / 100 \mathrm{ml}$. Total serum IgE $5 \mathrm{IU}$; specific IgE for cows' milk and egg were absent. Ig surface-bearing lymphocytes were $6 \%$.

\section{Inflammatory response}

Neutrophil cellular chemotaxis was almost absent, while random locomotion was normal, the RMI value being 110 . Humoral chemotaxis, opsonisation, phagocytosis, and candidacidal and bactericidal activities were all normal.

Clinical course. The baby was treated with daily oral doses of $40 \mathrm{mg}$ zinc sulphate. Within a few days the anorexia and listlessness had disappeared, the diarrhoea ceased, and he began to gain weight. The skin and nail lesions gradually resolved. In 2 months he gained $3 \mathrm{~kg}$. Plasma zinc level and neutrophil cellular chemotaxis became normal (Figure). After $2 \frac{1}{2}$ months the zinc medication was stopped: the cellular chemotaxis defect reappeared, while random mobility was normal (RMI 95);

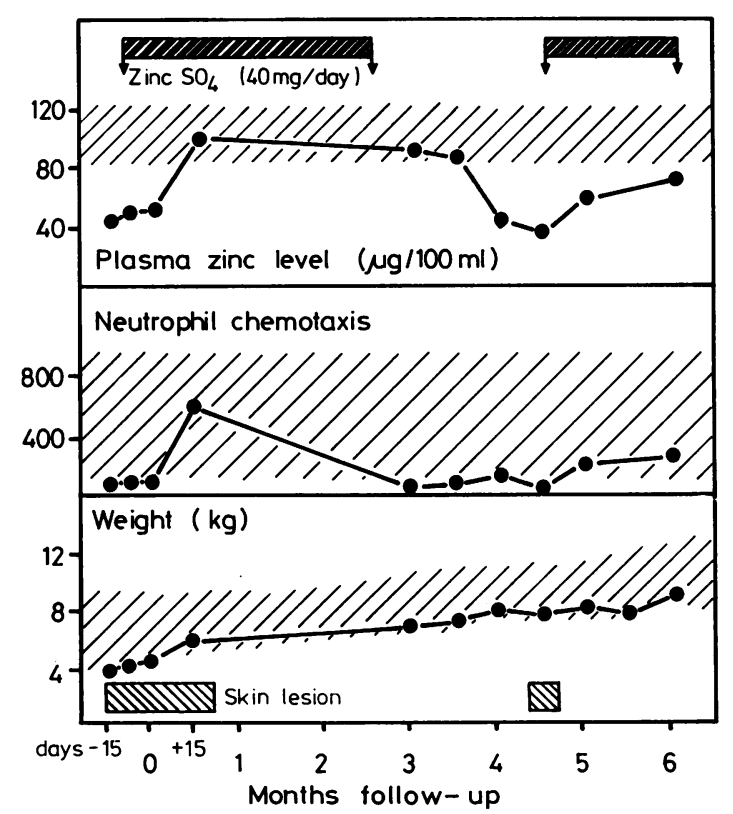

Figure Plasma zinc levels, polymorphonuclear neutrophil cellular chemotaxis, and weight in an infant with acrodermatitis enteropathica treated with zinc $\mathrm{SO}_{4}$. 
plasma zinc gradually decreased, and the skin lesions recurred after 6 weeks. Treatment with zinc was then reinstituted and the symptoms and signs again reversed: most of the skin lesions cleared within 2 weeks, and neutrophil chemotaxis and the plasma zinc level returned to normal (Figure). Random locomotion was normal at all times.

\section{Discussion}

Experimental and clinical studies have shown that zinc plays an important role in some immunological functions, particularly cellular immune response. ${ }^{6}{ }^{16}$ The relationship between zinc and immune response has yet to be clarified; zinc is an essential component of more than 40 metalloenzymes-such as deoxyribonucleic acid, ribonucleic acid-polymerase, and thymidine kinase. This role of zinc in nucleic acid metabolism and protein synthesis may explain the relatively high zinc requirement of the faster turnover cells such as the cells involved in immune response. Investigations of the immune system in our infant, in the presence of the zinc deficiency, showed normal numbers and function of T- and B-lymphocytes, with a severe defect of neutrophil cellular chemotaxis: in vitro assays of other neutrophil functions (random motility, phagocytosis, and bactericidal activity) remained unaffected. This dissociation between normal random motility and impaired chemotaxis must be stressed. There is growing evidence that various cellular mechanisms may enhance the ability of neutrophils to move spontaneously and to move towards attractant molecules. ${ }^{13}$ Recent studies suggest that while functioning microfilaments are probably necessary for neutrophil migration, intact microtubules are essential for normal pseudopod formation and orientation, and for maximal unidirectional migration during chemotaxis. ${ }^{14}$ To quote Repo: 'In a true chemotaxis defect directional response is impaired while spontaneous locomotion of the cells may be not'. ${ }^{13}$ Furthermore, zinc seems to be involved in microtubule function ${ }^{15}$ and its deficiency could explain the impairment of cellular motile response to a chemoattractant stimulus observed in AE patients. This hypothesis is in keeping with the obvious relation between zinc sulphate intake and the correction of neutrophil mobility function seen in the present case and reported in another. ${ }^{6}$ When treatment with zinc was stopped, the cellular chemotaxis defect reappeared in the absence of any other detectable immunological abnormality; zinc plasma level decreased after 4 weeks, and skin lesions reappeared after 6 weeks. These observations suggest that neutrophil chemotaxis is zinc-dependent. In conclusion, AE provides a natural experi- mental model with which to investigate the effects of zinc on the immune system.

This work was supported by a grant from the National Research Council.

\section{References}

1 Neldner K H, Hambidge K M. Zinc therapy of acrodermatitis enteropathica. $N$ Engl J Med 1975; 292: 879-82.

2 Moynahan E J. Letter: Zinc deficiency and cellular immune deficiency in acrodermatitis enteropathica in man and zinc deficiency with thymic hypoplasia in Fresian calves; a possible genetic link. Lancet 1975; ii: 710.

3 Eckhert C D, Sloan M V, Duncan J R, Hurley L S. Zinc binding: a difference between human and bovine milk. Science 1977; 195: 789-90.

4 Julius R, Schulkind M, Sprinkle T, Rennert O. Acrodermatitis enteropathica with immune deficiency. J Pediatr 1973; 83: 1007-11.

5 Guiraldes E, Sorensen R, Gutierrez C, Cofre P, Gonzalez B. Letter: Zinc sulphate for acrodermatitis enteropathica. Lancet 1975 ; ii: $710-1$.

6 Weston W L, Huff J C, Humbert J R, Hambidge K M, Nelder K H, Walravens P A. Zinc correction of defective chemotaxis in acrodermatitis enteropathica. Arch Dermatol 1977; 113: 422-5.

7 Rezza E, Aiuti F, Businco L, Castello M A. Familial lymphopenia with T lymphocyte defect. $J$ Pediatr 1974; 84: 78-82.

8 Nelson R D, Quie P G, Simmons R L. Chemotaxis under agarose: a new and simple method for measuring chemotaxis and spontaneous migration of human polymorphonuclear leukocytes and monocytes. J Immunol 1975; 115: $1650-6$.

9 D'Amelio R, Arranhado E, Le Moli S, Rossi P. Study of chemotaxis by a modified method of migration under agarose gel. Boll Ist Sieroter Milan 1979; 58: 306-14.

10 Quie P G, White J G, Holmes B, Good R A. In vitro bactericidal capacity of human polymorphonuclear leukocytes diminished activity in chronic granulomatous disease of childhood. J Clin Invest 1967; 46: 668-79.

11 Laurenti F, Battaglia M, Lendvai D, Midulla M, Rezza E. Micrometodo semplificato per la determinazione dell' attività candidacida dei leucociti. Ann Sclavo 1976; 18: 574-84.

12 Falchuk K H, Evenson M, Vallee B L. A multichannel atomic absorption instrument: simultaneous analysis of zinc, copper, and cadmium in biologic materials. Anal Biochem 1974; 62: 255-67.

13 Repo H, Kostiala A A I, Kosunen T V. Use of leukocyte migration under agarose to study spontaneous and directed locomotion of leukocytes. Immunology 1978; 35: 539-48.

14 Malech H L, Root R K, Gallin J I. Structural analysis of human neutrophil migration. J Cell Biol 1977; 75: 666-93.

15 Falchuk K H, Krishan A, Vallee B L. DNA distribution in the cell cycle of Euglena gracilis. Cytofluorometry. Biochemistry 1975; 14: 3439-44.

16 Golden M H N, Golden B E, Harland P S E G, Jackson A A. Zinc and immunocompetence in protein-energy malnutrition. Lancet 1978; ii: 1226-7.

Correspondence to Professor L Businco, 1st Department of Paediatrics, University of Rome, Viale Regina Elena 324, 00161 Rome; Italy. 